\title{
Physical activity and nutrition recommendations for weight management during breast cancer treatment
}

\author{
Karen Y Wonders ${ }^{1,2 *}$ and Brittany Stout ${ }^{2}$ \\ ${ }^{1}$ Department of Kinesiology and Health, Wright State University, Dayton, OH, USA \\ ${ }^{2}$ Maple Tree Cancer Alliance, Dayton, OH, USA
}

\begin{abstract}
The treatment of breast cancer can lead to an undesirable increase in weight. However, there are ways to combat this effect through exercise and proper nutrition. Physical activity and healthy eating habits will provide a trickle-down effect in health, promoting improvements in other areas that may cause weight gain, including slowed metabolism and estrogen reduction. Even if the ideal weight is not achieved, weight losses of 5-10\% as a result of healthy eating and physical activity are still likely to have significant health benefits to the breast cancer survivor.
\end{abstract}

\section{Introduction}

In the United States, women have a 1 in 8 lifetime risk of developing breast cancer. Cancer and its associated treatments produce side effects that can significantly impact an individual's eating habits, appetite, energy levels, and body weight. Many patients tend to lose weight during treatment. However, women treated for hormone-driven breast cancer tend to gain as much as twenty-five pounds during treatment. Previous research has identified that premenopausal women receiving adjuvant chemotherapy are at the greatest risk of weight gain during breast cancer treatment [1]. During adjuvant chemotherapy treatment, there tends to be a shift from lean body mass to mostly fat mass and an increase in weight. This pattern is consistent with sarcopenic obesity, and is associated with chronic corticosteroid use, menopause, physical inactivity, and aging [2]. If left unaddressed, overweight and obesity $(\mathrm{BMI} \geq 25.0)$ can have negative implications during recovery from cancer, as it increases the risk of breast cancer mortality [3-5], as well as treatment effects such as less favorable lymph node status, and lymphedema [6]. In addition, excess weight gain also increases the risk of other health problems, including heart disease and diabetes $[7,8]$. Recognizing this impact, the purpose of this investigation was to analyze the current literature addressing weight gain during breast cancer treatment and create an action plan to address this issue in survivors.

\section{Contributing factors to weight gain in breast cancer}

\section{Adjuvant chemotherapy}

During chemotherapy treatments, metabolism slows down, making it difficult for the body to maintain a healthy weight. These invasive treatments often lead to the use of corticosteroids for relief of nausea, swelling, and/or to combat reactions and side effects to chemotherapy treatment. Corticosteroid use is associated with increased appetite and fatty tissue [9]. Additionally, many chemotherapy treatments given to pre-menopausal women promote an early transition into menopause, where women tend to experience a reduction of lean body mass and an increase in fat mass [1].

\section{Hormone therapy}

Hormonal therapies are used to slow or stop the growth of cancers that use hormones to grow, such as certain forms of breast cancer. Hormone therapy works to block the ability of the body to produce hormones. Estrogen, however, is still produced and secreted from fatty tissue in the body. Because fatty tissue is the only thing left in the body producing estrogen, in some cases, the body will tend to hang on to fatty tissue [10]. Other side effects of hormone treatment include hot flashes, decreases in bone density, diarrhea, nausea, and fatigue.

\section{Physical inactivity}

The side effects associated with chemotherapy treatments (stress, fatigue, nausea, pain) make it difficult for cancer patients to have the motivation and stamina necessary to be active [9]. Physical inactivity during adjuvant chemotherapy treatments results in reduced energy expenditure, decreases in lean body mass, and weight gain [1]. In a study by Denmark-Wahnefried et al. [11], physical inactivity was cited as the primary factor responsible for weight gain during treatment. Additionally, women who were sedentary prior to a breast cancer diagnosis had an increased risk of weight gain during adjuvant chemotherapy [1]. This and other studies [12] suggest that physical inactivity is one of the primary factors related to weight gain in breast cancer patients. Therefore, appropriate exercise programs can aid in the prevention or decrease in body fat during treatment.

The primary reason for lack of physical activity during adjuvant chemotherapy is the accompanied cancer-related fatigue, which is a debilitating side effect of treatment experienced by a majority of breast cancer patients [13]. This specific type of fatigue is often times not relieved with rest. Actually, the fatigue levels can worsen with too much

Correspondence to: Karen Wonders, Ph.D., FACSM, Wright State University, 3640 Colonel Glenn Hwy, 301 Nutter Center, Dayton, OH 45435, USA, Tel: 9377752840; E-mail: karen.wonders@wright.edu

Received: May 29, 2017; Accepted: June 15, 2017; Published: June 17, 2017 
rest. However, research indicates that moderate intensity physical activity can significantly improvement cancer-related fatigue during cancer treatment [14]. Exercise not only allows for the management of fatigue, but also promotes an increase in metabolism, promoting weight loss.

\section{Recommendations for weight management}

Recent data suggest that the avoidance of weight gain during treatment for breast cancer may be important for survivors, regardless of their weight status at the time of diagnosis. In addition, intentional weight loss following treatment recovery among those who are overweight and obese is linked to health-related benefits, such as reduced recurrence and improved overall survival rates [15]. In fact, the Women's Intervention Nutrition Study (WINS) found that a low-fat diet that resulted in a 6-pound weight loss reduced the risk of recurrence among postmenopausal breast cancer survivors [16]. After cancer treatment, weight gain should be managed through a combination of healthy diet and physical activity.

\section{Physical activity recommendations}

Research strongly supports physical activity as save and effective during cancer recovery, suggesting that those who are active have higher survival rates $[17,18]$ compared to those who remain sedentary. One study in particular found that breast cancer survivors who completed approximately 3 hours of moderate-intense exercise per week had a $30 \%$ lower overall mortality compared to less active survivors [17]. In addition, a meta analysis of breast cancer survivors from 16 studies found that those who got the recommended 150 minutes of exercise each week had an $11 \%$ reduction in breast cancer mortality, and a $24 \%$ lower risk of overall mortality [19]. In addition, remaining physically active during recovery from breast cancer can also help to improve quality of life, body image, mood, bone health, and physical condition, while at the same time reducing fatigue, stress, and anxiety [20-26]. In light of this and other findings, the American Cancer Society has made the following recommendations for breast cancer survivors to maintain their weight [27]:

- Avoid inactivity and return to normal daily activity as soon as possible after diagnosis.

- Get regular physical activity.

- Aim for at least 150 minutes of exercise each week.

- $\quad$ Perform strength training exercises at least twice each week.

Most activity recommendations for breast cancer patients include low impact activities such as walking, biking, or swimming. These specific types of activities protect and optimize the immune system while the patient is undergoing treatment [28].

\section{Nutrition recommendations}

At present, a specific diet proven to increase breast cancer survival has not been identified. However, eating a healthy diet will promote overall health and helps to protect the body from other diseases [29]. During breast cancer treatment, the overall nutritional goals should be to prevent or resolve nutrient deficiencies, achieve or maintain a healthy weight, preserve lean body mass, and reduce nutrition-related side effects.

Some guidelines put forth by the American Cancer Society to maximize quality of life include:
- $\quad$ Limit high-calorie foods and beverages.

- Reduce consumption of white flour.

- Choose $100 \%$ whole grain foods (brown rice, quinoa, whole grain breads).

- $\quad$ Eat at least $2 \frac{1}{2}$ cups of fruits and vegetables each day.

- Limit intake of red and processed meat.

- Limit saturated and trans fats, found in red meat, fried foods, margarine, and donuts.

- $\quad$ Eat "good" fats (polyunsaturated and monounsaturated fats), found in olive and canola oil, nuts, natural nut butters, and avocados.

Specifically, studies have found that breast cancer survivors who ate a diet rich in carotenoids had a higher disease-free survival than those with lower levels [30]. In addition, reduction in fat intake may help a breast cancer survivor to lose weight [16], which helps to improve disease-free survival. Finally, diets high in soy are linked to a decrease in both breast cancer recurrence and breast cancer mortality [31-34]. Finally, it is important to understand eating habits in order to find patterns that may lead to overeating when food cravings hit. Watching portion sizes and eating smaller meals throughout the day will maintain metabolic functioning and feelings of satiety, both of which will help maintain a healthy weight. Finally, it is worth noting that even if ideal weight is not achieved, weight losses of $5-10 \%$ as a result of healthy eating and physical activity are still likely to have significant health benefits to the breast cancer survivor [35].

\section{Conclusions}

The treatment of breast cancer can lead to an undesirable increase in weight. However, there are ways to combat this effect through exercise and proper nutrition. Physical activity and healthy eating habits will provide a trickle-down effect in health, promoting improvements in other areas that may cause weight gain, including slowed metabolism and estrogen reduction.

\section{References}

1. Goodwin PJ (2001) Weight gain in early-stage breast cancer: where do we go from here? J Clin Oncol 19: 2367-2369. [Crossref]

2. Demark-Wahnefried W, Rimer BK, Winer EP (1997) Weight gain in women diagnosed with breast cancer. J Am Diet Assoc 97: 519-526, 529. [Crossref]

3. Kroenke CH, Chen WY, Rosner B, Holmes MD (2005) Weight, weight gain, and survival after breast cancer diagnosis. J Clin Oncol 23: 1370-1378. [Crossref]

4. Majed B, Moreau T, Senouci K, Salmon RJ, Fourquet A, et al. (2008) Is obesity an independent prognosis factor in woman breast cancer? Breast Cancer Res Treat 111: 329-342. [Crossref]

5. Protani M, Coory M, Martin JH (2010) Effect of obesity on survival of women with breast cancer: systematic review and meta-analysis. Breast Cancer Res Treat 123(3): 627-635. [Crossref]

6. Chlebowski RT, Aiello E, McTiernan A (2002) Weight loss in breast cancer patient management. J Clin Oncol 20: 1128-1143. [Crossref]

7. Jeon YW, Kang SH, Park MH, Lim W, Cho SH, et al. (2015) Relationship between body mass index and the expression of hormone receptors or human epidermal growth factor receptor 2 with respect to breast cancer survival. BMC Cancer 15: 865. [Crossref]

8. National Heart, Lung, and Blood Institute (2012) What are overweight and obesity? http://www.nhlbi.nih.gov/health/health-topics/topics/obe.

9. Breast Cancer Treatment and Weight Changes. (n.d.). WebMD. http://www.webmd com/breast-cancer/breast-cancer-and-weight-changes\#1

10. Smith AJ, Phipps WR, Thomas W, Schmitz KH, Kurzer MS (2013) The Effects of Aerobic Exercise on Estrogen Metabolism in Healthy Premenopausal Women. Cancer 
Epidemiol Biomarkers Prev 22(5): 756-764. [Crossref]

11. Demark-Wahnefried W, Winer EP, Rimer BK (1993) Why women gain weight with adjuvant chemotherapy for breast cancer. J Clin Oncol 11: 1418-1429. [Crossref]

12. Hormone Therapy for Breast Cancer (2017) National Cancer Institute. https://www. cancer.gov/types/breast/breast-hormone-therapy-fact-sheet

13. Berger AM, Gerber LH, Mayer DK (2012) Cancer-related fatigue: implications for breast cancer survivors. Cancer 118: 2261-2269. [Crossref]

14. Schneider CM, Hsieh CC, Sprod LK, Carter SD, Hayward R (2007) Effects of supervised exercise training on cardiopulmonary function and fatigue in breast cancer survivors during and after treatment. Cancer 110: 918-925.

15. Look AHEAD Research Group, Wing RR (2010) Long-term effects of a lifestyle intervention on weight and cardiovascular risk factors in individuals with type 2 diabetes mellitus: four-year results of the Look AHEAD trial. Arch Intern Med 170: 1566-1575. [Crossref]

16. Chlebowski RT, Blackburn GL, Thomson CA, Nixon DW, Shapiro A, et al. (2006) Dietary fat reduction and breast cancer outcome: interim efficacy results from the Women's Intervention Nutrition Study. J Natl Cancer Inst 98: 1767-1776. [Crossref]

17. Fong DY, Ho JW, Hui BP, Lee AM, Macfarlane DJ, et al. (2012) Physical activity for cancer survivors: meta-analysis of randomised controlled trials. BMJ 344: e70. [Crossref]

18. Holick CN, Newcomb PA, Trentham-Dietz A, Titus-Ernstoff L, Bersch AJ, et al. (2008) Physical activity and survival after diagnosis of invasive breast cancer. Cancer Epidemiol Biomarkers Prev 17(2): 379-86. [Crossref]

19. Schmid D, Leitzmann MF (2014) Association between physical activity and mortality among breast cancer and colorectal cancer survivors: a systematic review and metaanalysis. Ann Oncol 25(7): 1293-1311. [Crossref]

20. Mishra SI, Scherer RW, Geigle PM, Berlanstein DR, Topaloglu O, et al. (2012) Exercise interventions on health-related quality of life for cancer survivors. Cochrane Database Syst Rev. [Crossref]

21. Kwan ML, Ergas IJ, Somkin CP, Quesenberry CP Jr, Neugut AI, et al. (2010) Quality of life among women recently diagnosed with invasive breast cancer: the Pathways Study. Breast Cancer Res Treat 123: 507-524. [Crossref]

22. Leung J, Smith MD, McLaughlin D (2016) Inequalities in long term health-related quality of life between partnered and not partnered breast cancer survivors through the mediation effect of social support. Psychooncology 25(10): 1222-1228. [Crossref]

23. Shapiro SL, Lopez AM, Schwartz GE, Bootzin R, Figueredo AJ, et al. (2001) Quality of life and breast cancer: relationship to psychosocial variables. J Clin Psychol 57: 501-519. [Crossref]
24. Duijts SF, Faber MM, Oldenburg HS, van Beurden M, Aaronson NK (2011) Effectiveness of behavioral techniques and physical exercise on psychosocial functioning and health-related quality of life in breast cancer patients and survivors-a meta-analysis. Psychooncology 20(2): 115-126. [Crossref]

25. Buffart LM, van Uffelen JG, Riphagen II, Brug J, van Mechelen W, et al. (2012) Physical and psychosocial benefits of yoga in cancer patients and survivors, a systematic review and meta-analysis of randomized controlled trials. BMC Cancer 12: 559.

26. Meneses-Echávez JF, González-Jiménez E, Ramírez-Vélez R (2015) Effects of supervised exercise on cancer-related fatigue in breast cancer survivors: a systematic review and meta-analysis. BMC Cancer 15: 77.

27. Kushi LH, Doyle C, McCullough M, Rock CL, Demark-Wahnefried W, et al. (2012) American Cancer Society Guidelines on nutrition and physical activity for cancer prevention: reducing the risk of cancer with healthy food choices and physical activity. CA Cancer J Clin 62(1): 30-67.

28. Courneya, KS, Segal, RJ, Mackey JR, Gelmon K, Reid RD, et al (2007) Effects of Aerobic and Resistance Exercise in Breast Cancer Patients Receiving Adjuvant Chemotherapy: A Multicenter Randomized Controlled Trial. J Clin Oncol 25(28): 4396-4404. [Crossref]

29. Rock CL, Doyle C, Demark-Wahnefried W, Meyerhardt J, Courneya KS, et al. (2012) Nutrition and physical activity guidelines for cancer survivors. CA Cancer J Clin 62: 243-274. [Crossref]

30. Rock CL, Natarajan L, Pu M, Thomson CA, Flatt SW, et al. (2009) Longitudinal biological exposure to carotenoids is associated with breast cancer-free survival in the Women's Healthy Eating and Living Study. Cancer Epidemiol Biomarkers Prev 18(2): 486-494. [Crossref]

31. Wu AH, Lee E, Vigen C (2013) Soy isoflavones and breast cancer. Am Soc Clin Oncol Educ Book . [Crossref]

32. Shu XO, Zheng Y, Cai H, Gu K, Chen Z, et al. (2009) Soy food intake and breast cancer survival. JAMA 302: 2437-2443. [Crossref]

33. Nechuta SJ, Caan BJ, Chen WY, Lu W, Chen Z, et al. (2012) Soy food intake after diagnosis of breast cancer and survival: an in-depth analysis of combined evidence from cohort studies of US and Chinese women. Am J Clin Nutr 96: 123-132. [Crossref]

34. Chi F, Wu R, Zeng YC, Xing R, Liu Y, et al. (2013) Post-diagnosis soy food intake and breast cancer survival: a meta-analysis of cohort studies. Asian Pac J Cancer Prev 14: 2407-2412. [Crossref]

35. National Heart, Lung, and Blood Institute (2011) Aim for a Healthy Weight. Bethesda, MD. http://www.nhlbi.nih.gov/health/public/heart/obesity/lose_wt/index.htm

Copyright: $₫ 2017$ Wonders KY. This is an open-access article distributed under the terms of the Creative Commons Attribution License, which permits unrestricted use, distribution, and reproduction in any medium, provided the original author and source are credited. 